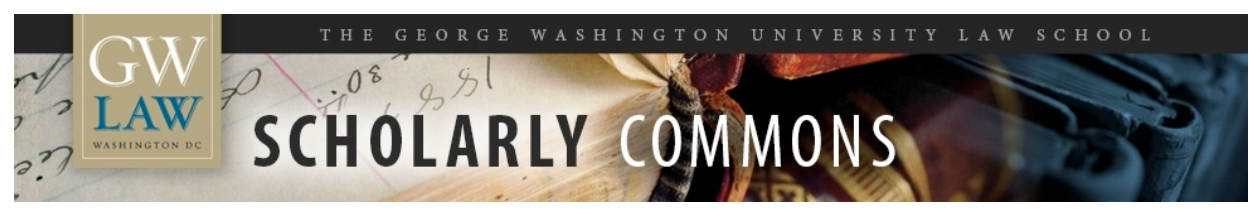

\title{
Biased Assimilation, Polarization, and Cultural Credibility: An Experimental Study of Nanotechnology Risk Perceptions
}

\author{
Donald Braman \\ George Washington University Law School, dbraman@law.gwu.edu \\ Dan M. Kahan \\ Paul Slovic \\ John Gastil \\ Geoffrey L. Cohen
}

See next page for additional authors

Follow this and additional works at: https://scholarship.law.gwu.edu/faculty_publications

Part of the Law Commons

\section{Recommended Citation}

Braman, Donald; Kahan, Dan M.; Slovic, Paul; Gastil, John; Cohen, Geoffrey L.; and Kysar, Douglass A., "Biased Assimilation, Polarization, and Cultural Credibility: An Experimental Study of Nanotechnology Risk Perceptions" (2008). GW Law Faculty Publications \& Other Works. 197.

https://scholarship.law.gwu.edu/faculty_publications/197

This Article is brought to you for free and open access by the Faculty Scholarship at Scholarly Commons. It has been accepted for inclusion in GW Law Faculty Publications \& Other Works by an authorized administrator of Scholarly Commons. For more information, please contact spagel@law.gwu.edu. 
Authors

Donald Braman, Dan M. Kahan, Paul Slovic, John Gastil, Geoffrey L. Cohen, and Douglass A. Kysar 


\section{${ }^{\text {the }}$ Cultural Cognition Project}

Report:

Biased Assimilation, Polarization, and Cultural Credibility:

An Experimental Study of Nanotechnology Risk Perceptions

Dan M. Kahan

Yale Law School

John Gastil

University of Washington
Paul Slovic

Decision Research

Geoffrey Cohen

University of Colorado
Donald Braman

George Washington University

Law School

Douglas Kysar

Cornell University School of Law

February 4, 2008

Research Supported by

National Science Foundation, Grant SES 0621840

The Project on Emerging Nanotechnologies

Woodrow Wilson International Center for Scholars

The Oscar Ruebhausen Fund at Yale Law School 
The Cultural Cognition Project at Yale Law School is a group of scholars from Yale and other universities interested in studying how cultural values shape the public's risk perceptions and related policy beliefs. In research funded by the National Science Foundation and the Oscar M. Ruebhausen Fund at Yale Law School, Project members are using the methods of various disciplines - including social psychology, anthropology, communications, and political science- to chart the impact of this process and to identify the mechanisms through which it operates. The Project also has an explicit normative objective: to identify democratic procedures that enable society to resolve culturally grounded differences in belief in a manner that is both congenial to people of diverse cultural outlooks and consistent with sound public policymaking. For more information about the Project, go to http://research.yale.edu/culturalcognition/.

The Project on Emerging Nanotechnologies is an initiative launched by the Woodrow Wilson International Center for Scholars and The Pew Charitable Trusts in 2005. It is dedicated to helping business, government, and the public anticipate and manage possible health and environmental implications of nanotechnology. For more information about the Project, go to www.nanotechproject.org.

The opinions expressed in this report are those of the authors and do not necessarily reflect views of the Woodrow Wilson International Center for Scholars or The Pew Charitable Trusts. 


\section{About the Authors}

Dan M. Kahan is the Elizabeth K. Dollard Professor of Law at Yale Law School. His principal areas of research include the legal and policy significance of emotions, social norms, and public risk perceptions. He has published widely in academic journals including the Harvard Law Review, the Columbia Law Review and the University of Chicago Law Review, and is co-author (with Tracey Meares) of Urgent Times: Policing and Rights in Inner-City Communities (Beacon Press 1999) (with Tracey Meares). He received his J.D. from Harvard Law School in 1989.

Paul Slovic, Professor of Psychology at the University of Oregon and founder and President of Decision Research, studies human judgment, decisionmaking, and risk analysis. He and his colleagues worldwide have developed methods to describe risk perceptions and measure their impacts on individuals, industry, and society. He publishes extensively and serves as a consultant to industry and government. Dr. Slovic is a Past President of the Society for Risk Analysis and in 1991 received the group's Distinguished Contribution Award. In 1993 he received the Distinguished Scientific Contribution Award from the American Psychological Association. In 1995 he received the Outstanding Contribution to Science Award from the Oregon Academy of Science. He has received honorary doctorates from the Stockholm School of Economics (1996) and the University of East Anglia (2005).

Donald Braman is an Associate Professor of Law at George Washington University. His principal areas of research include the familial and community effects of criminal sanctions, public attitudes towards punishments, and the influence of cultural values on risk perception and legal debates. He has published widely in academic journals and is co-author of Doing Time on the Outside: Incarceration and Family Life in Urban America (University of Michigan Press 2004). He received his Ph.D. from Yale University (Anthropology) in 2002 and his J.D. from Yale Law School in 2005.

John Gastil, Associate Professor, has taught at the University of Washington since 1998. Gastil teaches courses on small group decisionmaking, political deliberation, and public scholarship. From 1994-1997, Gastil conducted public opinion research at the University of New Mexico Institute for Public Policy. He received a Ph.D. degree in communication from the University of Wisconsin-Madison in 1994 and a B.A. in political science from Swarthmore College in 1989. He is the author of Political Communication and Deliberation, The Deliberative Democracy Handbook (co-edited with Peter Levine), By Popular Demand, and Democracy in Small Groups.

Geoffrey Cohen is an Associate Professor at the University of Colorado at Boulder. Much of his research concerns the processes of self-evaluation and identity maintenance. One area of research addresses the effects on achievement motivation of individuals' group memberships, with a focus on the role of social stereotypes in shaping intellectual identity and performance. A second research area links resistance to probative information, and intransigence in negotiation and social conflict, to concerns of identity maintenance. His laboratory examines the psychological processes underlying significant social problems and phenomena and seeks to use the acquired knowledge of basic processes to develop, refine, and test intervention strategies. Professor Cohen received his Ph.D. from Stanford University in 1998.

Douglas Kysar, Professor of Law at Cornell University School of Law, will join the Yale Law School in February 2008. He, is Societal and Ethical Issues Coordinator for the National Nanotechnology Infrastructure Network, an integrated networked partnership of user facilities supported by the National Science Foundation. His works have appeared in various journals, including the Harvard Law Review, the Columbia Law Review, and the Cornell Law Review. Two of Professor Kysar's articles have been selected for presentation in the environmental law category at the Stanford-Yale Junior Faculty Forum. He has been a Visiting Associate Professor at Harvard Law School and at Yale Law School, and a Visiting Scholar at the Universitat Pompeu Fabra in Barcelona, Spain. 


\title{
Biased Assimilation, Polarization, and Cultural Credibility: An Experimental Study of Nanotechnology Risk Perceptions
}

\author{
Cultural Cognition Project at Yale Law School
}

\author{
Dan M. Kahan \\ Yale Law School \\ John Gastil \\ University of Washington
}

\author{
Paul Slovic \\ Decision Research \\ Geoffrey Cohen \\ University of Colorado
}

\author{
Donald Braman \\ George Washington University Law \\ School \\ Douglas Kysar \\ Cornell University School of Law
}

\section{Introduction and Summary of Conclusions}

This report describes the results of the second in a series of ongoing experimental studies of public perceptions of the risks and benefits of nanotechnology. The studies are aimed at identifying how public attitudes toward nanotechnology are likely to evolve as the public learns more about this novel science. They also seek to identify concrete strategies for improving public understanding of scientific information on the risks and benefits of nanotechnology as such information is developed. The first study in this series found that when individuals who know little about nanotechnology are exposed to information about it, they tend to polarize in their opinions along lines that reflect their cultural predispositions toward technological and environmental risks generally (Kahan, Braman, Slovic, Gastil, \& Cohen 2008). This study examined whether and how the perceived cultural outlooks of information sources would affect public reactions to arguments about the risks and benefits of nanotechnology.

Key findings and conclusions were as follows:

1. When unattributed to identifiable advocates, arguments about the risks and benefits of nanotechnology generate polarization of beliefs. Relative to persons not exposed to such arguments, individuals exposed to opposing sets of arguments divide along various lines, including race and cultural orientation. The gap between people who are generally inclined to credit and those generally inclined to dismiss claims of environmental risk widens dramatically after exposure to such arguments.

2. When such arguments are attributed to identifiable advocates, the impact of the arguments on subjects is highly sensitive to the perceived cultural outlooks of the advocates. When persons of diverse cultural outlooks observe an advocate whose values they share advancing an argument they are predisposed to accept, and an advocate whose values they reject advancing an argument they are predisposed to resist, the usual association between persons' cultural worldviews and their positions on nanotechnology becomes more extreme. When those same advocates are assigned the opposite positions, however, individuals observing the debate form perceptions of nanotechnology risks diametrically opposed to the ones normally associated with their 
own cultural outlooks. Finally, when there is no consistent relationship between the perceived values of advocates and positions taken on nanotechnology risk and benefits, cultural polarization is neutralized.

3. These findings reinforce the conclusion, reached in the first study in this series, that a strategy of public education that focuses only on disseminating accurate information cannot reliably be expected to generate convergence on accurate public beliefs about the risks and benefits of nanotechnology. People tend to credit and dismiss arguments about nanotechnology in patterns that reflect their cultural predispositions toward environmental and technological risks, and thus polarize on cultural lines, a phenomenon known as biased assimilation and polarization. The delivery of arguments by qualified experts will not necessarily counteract this effect, and indeed could easily accentuate it, because of the tendency of persons to assign greater credibility to policy advocates who share their values and who, as a result, are likely to be espousing positions that fit listeners' cultural predispositions.

4. Scientists, policymakers, and others interested in promoting enlightened public evaluation of the best available information on nanotechnology risks should take affirmative steps to create a deliberative climate that neutralizes biased assimilation and polarization. One such step would be to assure that members of the public do not form the impression that there is a link between the cultural values of policy advocates and particular positions on nanotechnology risks. Since credibility depends on trust, which depends largely on shared cultural outlooks, parties interested in communicating accurate information should be attentive to assuring that they avail themselves of information providers of diverse cultural orientations. In this condition of "advocacy pluralism," members of the public are less likely to divide along cultural lines.

5. Additional research is warranted to identify further concrete steps that can be taken to assure a culturally unbiased deliberative climate for public evaluation of sound information on nanotechnology's risks and benefits.

\section{Toward a Comprehensive Strategy for Promoting Informed Understanding of Nanotech- nology's Risks and Benefits}

The future of nanotechnology will be determined in large measure by the public's assessment of its potential benefits and risks. The Cultural Cognition Project (CCP), with the support and collaboration of the Project on Emerging Nanotechnologies (PEN), is engaged in a series of studies to determine how the public's perceptions of those matters is likely to evolve. These studies are not aimed at promoting any particular view on the relative magnitude of the benefits and risks of nanotechnology - a matter that is likely not susceptible to definitive assessment at this time. The studies are motivated, however, by a commitment to identifying concrete steps that scientists, regulators, and others can take to assure that the public's assessment of nanotechnology's risks and benefits reflects the best available scientific information that is currently available and that will become available as evaluations of nanotechnology continue.

The first study conducted as part of this series underscored that such an outcome cannot necessarily be expected to occur spontaneously (Kahan, Slovic, Braman, Gastil, \& Cohen 2007; Kahan, Braman, Slovic, Gastil, \& Cohen 2008). That study used experimental methods to test a hypothesis suggested by existing public opinion polls relating to nanotechnology. Those polls show that the vast majority of the American public has heard little, if anything, about nanotech- 
nology, but that those who are relatively familiar with it view it favorably (Peter D. Hart Associates 2007). A hypothesis one might form on the basis of these polls, then, is that as they learn more about it, members of the public currently unfamiliar with nanotechnology will likewise form the view that the benefits of nanotechnology predominate over its risks.

The results of the first CCP/PEN study furnished no support for this hypothesis. That study demonstrated that, when supplied with information, individuals unfamiliar with nanotechnology do not respond in a uniformly positive way. Indeed, they do not respond uniformly at all. On the contrary, such individuals polarize along cultural lines: when exposed to the same body of balanced and accurate information, persons who hold relatively egalitarian and communitarian values infer that nanotechnology is risky, whereas persons who hold relatively individualistic values infer that it is not (Kahan, Braman, Slovic, Gastil, \& Cohen 2008).

This result derives from two interrelated psychological dynamics. One is cultural cognition, which refers to the tendency of people to conform their factual beliefs about putatively dangerous activities to their cultural appraisals of those activities (DiMaggio 1997; Douglas \& Wildavsky 1982; Kahan \& Braman 2006). It is easier, psychologically speaking, to believe that behavior one finds noble is socially beneficial, and that behavior one finds base is socially harmful, than vice versa. Persons with individualistic outlooks value commerce and markets, and are thus predisposed to discount claims that such activities pose dangers to the environment that would justify restricting them. Persons who hold egalitarian values, in contrast, are very sensitive to environmental and technological risks, recognition of which justifies regulating activitiescommerce and industry - that they view as sources of unjust forms of inequality. People who hold communitarian values also readily credit claims of environmental risk because they see unconstrained commercial activity as symbolic of unconstrained pursuit of self-interest (Kahan, Braman, Gastil, Slovic, \& Mertz 2007).

The other relevant dynamic is biased assimilation and polarization (Lord, Ross, \& Leper 1979). It has been shown that individuals are disposed to screen information in a biased way based on its consistency with their prior beliefs or predispositions (biased assimilation). As a result, when people with different beliefs and predispositions are exposed to factual information, they do not converge but rather grow even more extreme in their disagreements (polarization).

Putting these dynamics together, one would expect that when persons who are unfamiliar with nanotechnology are exposed to information about it, they would draw inferences from it consistent with their cultural predispositions toward environmental and technological risks generally. As a result, such individuals would polarize, rather than form a uniform, much less a uniformly positive, view. That is exactly what our experiment found.

Such a result suggests that one cannot take for granted the emergence of public consensus as sound scientific information about nanotechnology's risks and benefits is disseminated to the public. Those who find such information congenial to their values are likely to credit it, but those who find such information uncongenial will be inclined to dismiss it and rely instead on lesssound information that is more supportive of their predispositions.

This unhappy outcome, however, is not necessarily inevitable. Studies have identified various risk-communication techniques that counteract the biasing effects of cultural cognition (Cultural Cognition Project 2007; Kahan, Slovic, Braman, \& Gastil 2006). CCP and PEN are 
currently studying how these techniques can be adapted to promote informed understanding of the risks and benefits of nanotechnology. The study that forms the basis of this report identifies one such technique.

\section{Nanotechnology Risk Perceptions and the Cultural Credibility Heuristic}

\section{Overview}

The aim of the current study was to examine how the cultural credibility heuristic interacts with biased assimilation and polarization in the setting of nanotechnology risk perceptions. Because most individuals lack the time and expertise necessary to make sense of scientific information on risk and other policy issues, they naturally rely on those whom they trust to determine what information to believe. The people they are inclined to trust are those who share their cultural outlooks (Kahan, Slovic, Braman, \& Gastil 2006). This dynamic can accentuate cultural polarization if information providers and advocates themselves are generally divided along cultural lines - as one might expect them to be by virtue of cultural cognition. But the cultural credibility heuristic can also potentially ameliorate such polarization if information advocates take positions that run contrary to the cultural predispositions of those inclined to defer to them. The current study used experimental methods to examine these possible effects in the context of the debate about the risks and benefits of nanotechnology.

\section{Study design}

The study involved a sample of approximately 1,600 American adults and was conducted over a period of several weeks between June and August 2007. The subjects were drawn from a nationally representative panel recruited by Knowledge Networks and participated in experiments using Knowledge Network's on-line testing facilities. ${ }^{1}$

Data on various individual characteristics were measured before the study. These included subjects' socio-demographic characteristics, political ideologies, and party affiliations. They also included subjects' cultural worldviews, which were measured using two scales: (1) Hierarchy-Egalitarianism, which assesses subjects' relative preferences for forms of social organization that reflect authority and role-based prerogatives, on the one hand, versus forms that reflect highly egalitarian relations, on the other; and (2) Individualism-Communitarianism, which assesses their relative preference for forms of social organization that give priority to individual and collective claims, respectively (Kahan, Braman, Gastil, Slovic, \& Mertz 2007). Individuals were characterized as either "Hierarchs" or "Egalitarians" and as either "Individualists" or "Communitarians" depending on where their scores fell in relation to the median of all subjects on each scale.

The study occurred in two stages. The first stage evaluated how exposure to balanced arguments unattributed to identifiable advocates would influence subjects' perceptions of nanotechnology risks and benefits. The second evaluated how exposure to the same arguments

\footnotetext{
${ }^{1}$ Additional information on the characteristics of the sample and on Knowledge Networks' on-line testing facilities appears in Appendix B.
} 
would influence participants' perceptions when the arguments were attributed to advocates recognized as holding one or another set of cultural values.

\section{Stage 1: The polarizing effects of arguments}

The first stage of the current study involved approximately 800 subjects. Half the subjects (the "no-argument condition") received no information about nanotechnology aside from a brief description of it. ${ }^{2}$ The other half ("the argument condition") received brief and balanced arguments, one proposing the suspension of nanotechnology development pending further research into its potential risks, and the other defending continued development pending such research. ${ }^{3}$ Subjects' perceptions of the risks and benefits of nanotechnology were measured on a six-point scale composed of seven items. The scale was coded so that the higher the score, the greater the concern with nanotechnology risks relative to benefits. ${ }^{4}$ Much like the first CCP/PEN study of nanotechnology, this component of the current study permitted us to assess the effects of information exposure - albeit in a more argumentative form - on persons of different attributes.

As in the previous study, we found that the vast majority of the subjects (92\%) had heard "little" or "nothing" about nanotechnology before the study. Overall, subjects exposed to argumentative information did not form risk perceptions significantly different from those of individuals not exposed to such arguments. However, as in the previous study, we found that various groups exposed to information became polarized relative to groups not exposed to information (Table 1).

\footnotetext{
2 "Nanotechnology is a relatively new form of science that involves the ability to measure, see, predict, and make things on the extremely small scale of atoms and molecules. Materials created with nanotechnology can often be made to exhibit very different physical, chemical, and biological properties than their normal size counterparts." The instrument used for both stages of the study is attached as an Appendix A.

3 See Appendix A for the wording of the arguments.

4 The items included in the scale appear in Appendix A. The scale proved reliable in both conditions, but was more so in the argument condition $(\alpha=.84)$ than in the no-argument condition $(\alpha=.68)$. This is not at all surprising, because so few subjects $(8 \%)$ had heard more than "a little" about nanotechnology before the study, one would expect the perceptions of subjects afforded more information to display greater internal consistency.
} 


\section{Mean Risk Perceptions Across Conditions}

\begin{tabular}{|c|c|c|c|c|}
\hline & $\begin{array}{r}\text { No-Argument } \\
\text { Condition } \\
\end{array}$ & $\begin{array}{l}\text { Argument } \\
\text { Condition }\end{array}$ & Diff. & Polarization \\
\hline Overall & 3.64 & 3.66 & .02 & NA \\
\hline Male & 3.52 & 3.46 & -.06 & \\
\hline Female & 3.76 & 3.87 & .11 & .17 \\
\hline White & 3.65 & 3.59 & -.06 & \\
\hline Nonwhite & 3.64 & 3.85 & .21 & .27 \\
\hline Conservative & 3.72 & 3.65 & -.06 & \\
\hline Liberal & 3.55 & 3.48 & -.07 & -.01 \\
\hline Republican & 3.67 & 3.64 & -.04 & \\
\hline Democrat & 3.60 & 3.69 & .09 & .13 \\
\hline Hierarch & 3.65 & 3.64 & -.01 & \\
\hline Egalitarian & 3.65 & 3.70 & .05 & .06 \\
\hline Individ & 3.66 & 3.57 & -.10 & \\
\hline Commun & 3.63 & 3.76 & .12 & .22 \\
\hline Low Env Fear & 3.54 & 3.48 & -.06 & \\
\hline High Env Fear & 3.76 & 3.89 & .13 & .19 \\
\hline High Know & 3.35 & 2.73 & -.61 & \\
\hline Low Know & 3.67 & 3.64 & -.03 & .59 \\
\hline \multicolumn{5}{|c|}{$\begin{array}{l}N \approx 800 \text {, approximately } 400 \text { subjects per condition. Risk percep- } \\
\text { tions measured with a } 6 \text {-point scale. Polarization refers to increase } \\
\text { in size of difference of mean risk perceptions of paired groups } \\
\text { across conditions. Boldface type indicates that the degree of polari- } \\
\text { zation so measured was statistically significant }(p \leq .05) \text {. }\end{array}$} \\
\hline
\end{tabular}

Table 1. Effects of Unattributed Arguments Across Groups

One dimension along which polarization occurred was racial. Whereas whites and nonwhites in the no-argument condition held relatively uniform views, nonwhites were significantly more fearful than whites in the argument condition (Figure 1).

Subjects also polarized along cultural lines. Relative to their counterparts in the noargument condition, individualists in the argument condition grew less fearful and communitarians grew more fearful. A gulf also emerged between egalitarians and hierarchs and between conservatives and liberals, although the size of the degree of polarization was not statistically significant in either case.

Relative to the no-argument condition, women became more concerned, and men less, in the argument condition. The degree of cultural polarization measured in terms of mean risk scores missed statistical significance. However, a multivariate regression confirmed that being female predicted greater concern with nanotechnology risks in the argument condition (Table 2). 


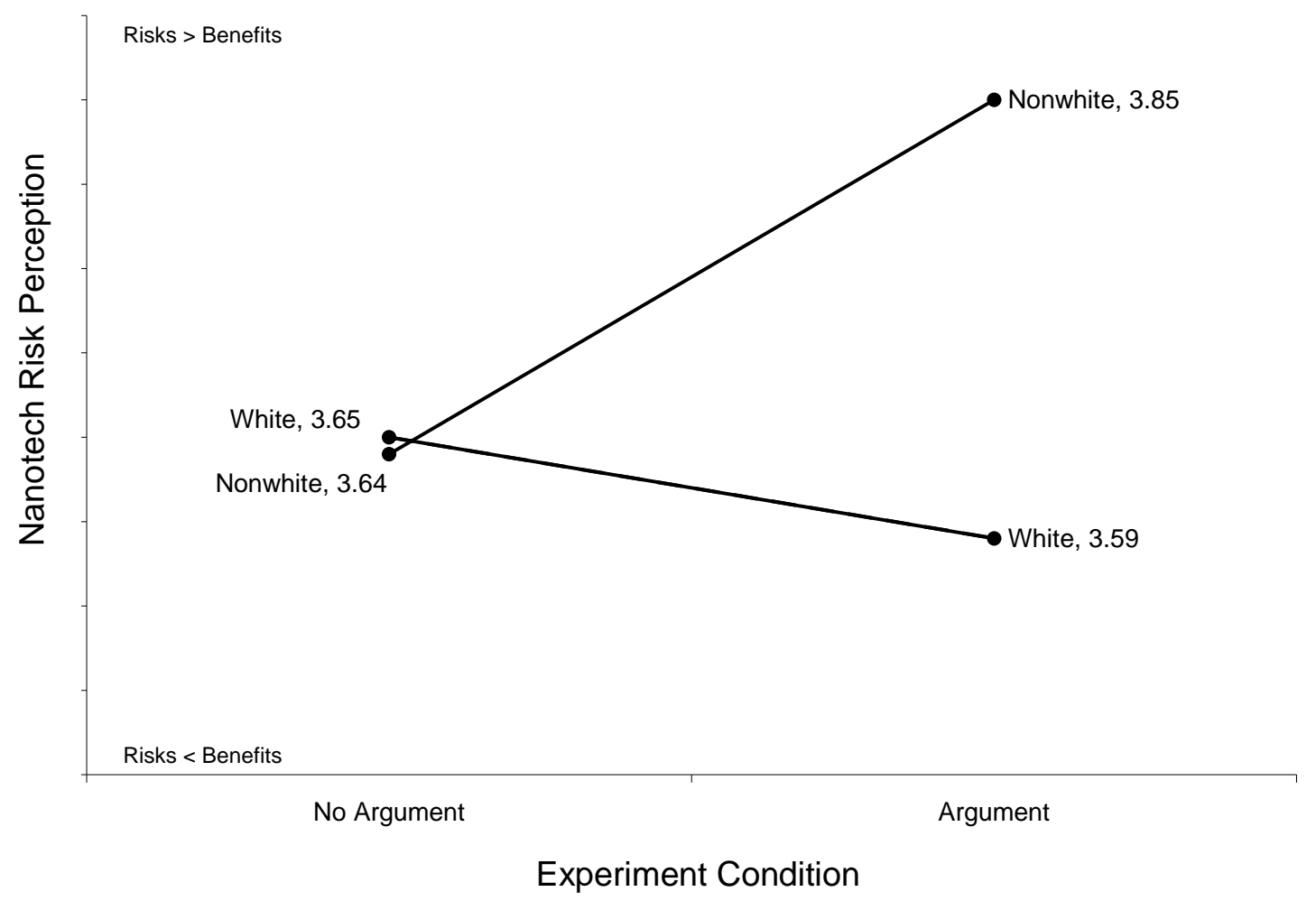

Figure 1. Argument Exposure and Racial Polarization

We also observed polarization among subjects based on their fear of environmental risks in general. Using items that measured our subjects' expressed concerns about global warming and nuclear power, we constructed a reliable "environmental fear" scale $(\alpha=.77) .{ }^{5}$ Low-fear subjects (those who displayed scores below the median degree of concern on the scale) had a higher degree of concern about nanotechnology risks than did high-fear subjects (those who displayed scores above the median) in both conditions. But again, the size of the gap between the two groups was dramatically larger in the argument condition (Figure 2). In other words, individuals disposed to worry about environmental risks can be expected to worry about nanotechnology when they first learn of it, and to become even more alarmed as they consider arguments about its risks and benefits.

Finally we found cultural polarization based on prior knowledge about nanotechnology. "High-knowledge" subjects (those who claimed they knew either a "moderate amount" or "a lot" about nanotechnology before the study) had less concern about risk than did "low-knowledge" subjects (those who claimed than that they knew "nothing" or "only a little") in both conditions. But the size of the differential was significantly larger in the argument condition.

\footnotetext{
5 See Appendix A for item wording.
} 


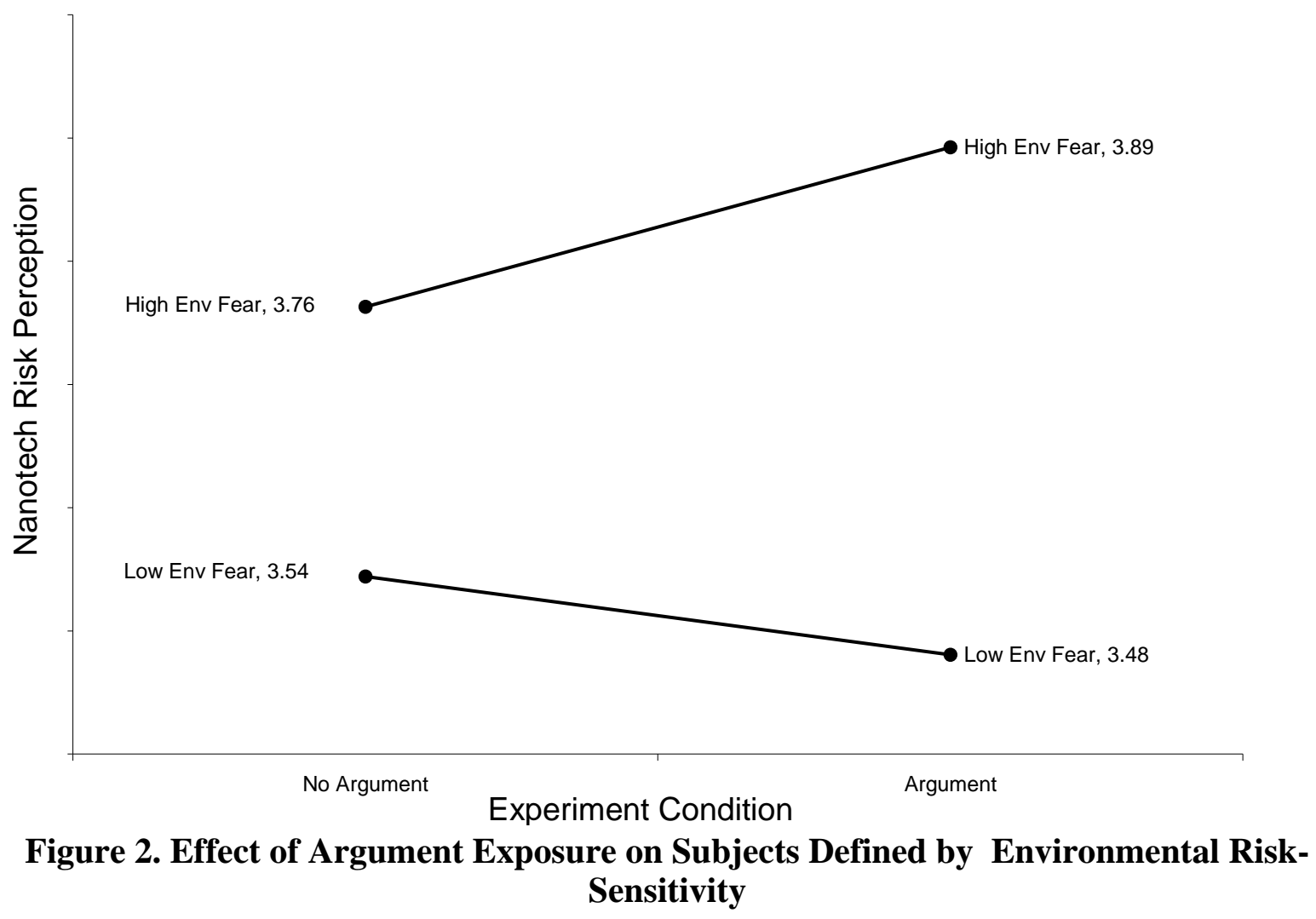

As we found in our previous experiment, then, the existing correlation between knowledge about nanotechnology and low concern for risk in the general population does not imply causation of the latter by the former. It suggests only that persons inclined to perceive the benefits of nanotechnology are more likely to learn about it on their own. When those who know little learn more, in contrast, those predisposed by cultural values or other influences to worry about environmental risks become more fearful. ${ }^{6}$

\footnotetext{
6 The public opinion polls contained in Peter D. Hart Associates (2007) do not demonstrate nearly as striking an effect from information exposure. This is not surprising since these polls reflect a within-subjects ("before-andafter") design, in which there is a tendency for subjects who initially express one view-particularly ones who acknowledge that they are unfamiliar with the issue in question - to indicate they have altered their position after receiving information in order to signal the socially desirable trait of open-mindedness. The between-subjects design used in this study and in our previous one avoids this effect and thus, we believe, furnishes a more valid indication of how information exposure is likely to affect members of the general public, particularly individuals who previously have not been exposed to comparable information.
} 


\begin{tabular}{lll} 
Conditions: & No Argument & Argument \\
\hline Female vs. Male & .097 & $.076^{*}$ \\
White & .007 & $-.098^{* *}$ \\
Age & .127 & .005 \\
Income & $-.103^{* *}$ & -.005 \\
Education Level & -.058 & $-.082^{*}$ \\
Republican vs. Democrat & .052 & $.093^{* *}$ \\
Independent vs. Democrat & .005 & .053 \\
Conservative vs. Liberal & .069 & .084 \\
Hierarchy vs. Egalitarianism & -.037 & .042 \\
Individualism vs. Communitarian & .026 & -.047 \\
Prior Knowledge of Nano & $-.160^{* * *}$ & $-.252^{* * *}$ \\
Environmental Risk Fear & $.162^{* * *}$ & $.266^{* * *}$ \\
\hline$R^{2}$ & .17 & .27 \\
\hline$N \approx 800$, approximately 400 subjects per condition. Dependent variable is \\
nanorisk. Regression coefficients are semi-partial correlations. $* * * p \leq .01, * *$ \\
$p \leq .05, * p \leq .10$.
\end{tabular}

Table 2. Multivariate Regression Analyses of Nanotechnology Risk Perceptions

\section{Stage 2: Credibility and polarization}

The second stage of the study involved an additional 800 subjects. These subjects were exposed to the same arguments as those in the argument condition of Stage 1 of the study. Now, however, the arguments were randomly assigned to advocates (fictional constructs presented to subjects in photographs as "policy experts at major universities") whom we had determined in separate pretests (involving different subjects) were perceived as holding different combinations of the values associated with the cultural worldview scales (Figure 3). Thereafter, subjects' views on the risks and benefits of nanotechnology were measured with the same scale used in Stage 1 of the study. 


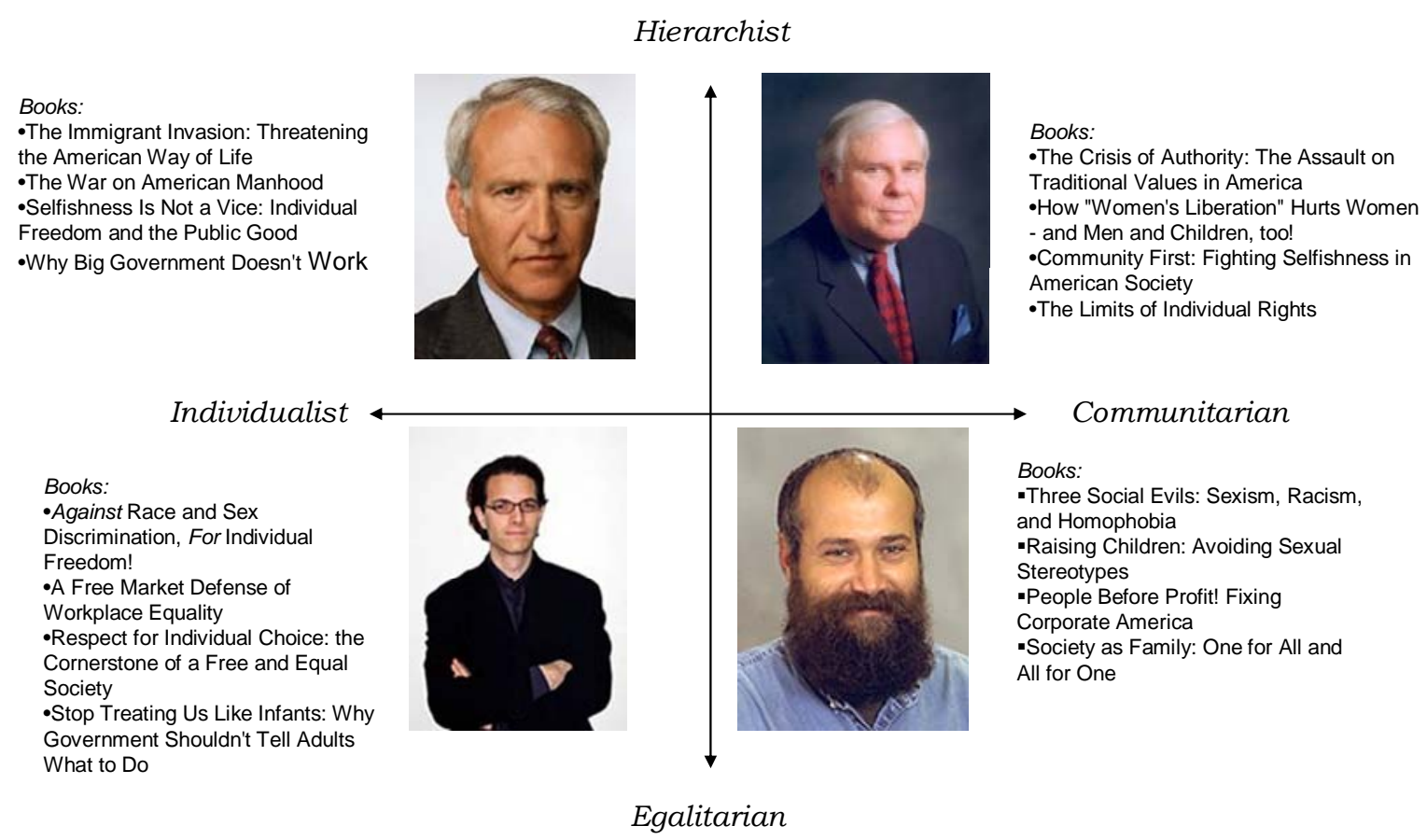

Figure 3. Culturally Identifiable Policy Advocates

The results revealed that cultural polarization interacts strongly with the relationship between subjects' cultural worldviews and the perceived worldviews of those advocating one position or another on nanotechnology (Figure 4). This was especially so along the HierarchyEgalitarianism dimension of cultural orientation. When subjects observed an egalitarian policy expert defending suspension of nanotechnology development pending additional research on risk, and a hierarchical one defending continued development pending such research, cultural polarization increased relative to that in the no-argument and argument conditions in stage 1. When, however, a hierarchical advocate defended suspension, and an egalitarian advocate defended continued development, subjects holding these respective worldviews swapped positions: among subjects confronted with this alignment of arguments and advocates, egalitarians became so convinced of nanotechnology's benefits that they displayed a more positive view of the balance of benefits and risks than did hierarchs.

Such a dramatic inversion of the cultural identity of advocates and the cultural resonances of arguments is unlikely to be experienced outside the laboratory. Less unrealistic, though, is the possibility of a pluralistic-argument environment - one in which advocates of diverse persuasions are as likely to be found on one side of the issue as on another. We found that in an experimental condition in which subjects were equally likely to see hierarchs and egalitarians on both sides of the issue - and for that reason seeing arguments among hierarchs and egalitarians as ones between them-cultural polarization was essentially eliminated. ${ }^{7}$ In a pluralistic-

${ }^{7}$ Differences in relative positions across conditions were statistically significant $(p<.05)$. 
argument environment, disagreement persists, but egalitarians are not significantly more or less likely to conclude that nanotechnology benefits predominate over risks than are hierarchs.

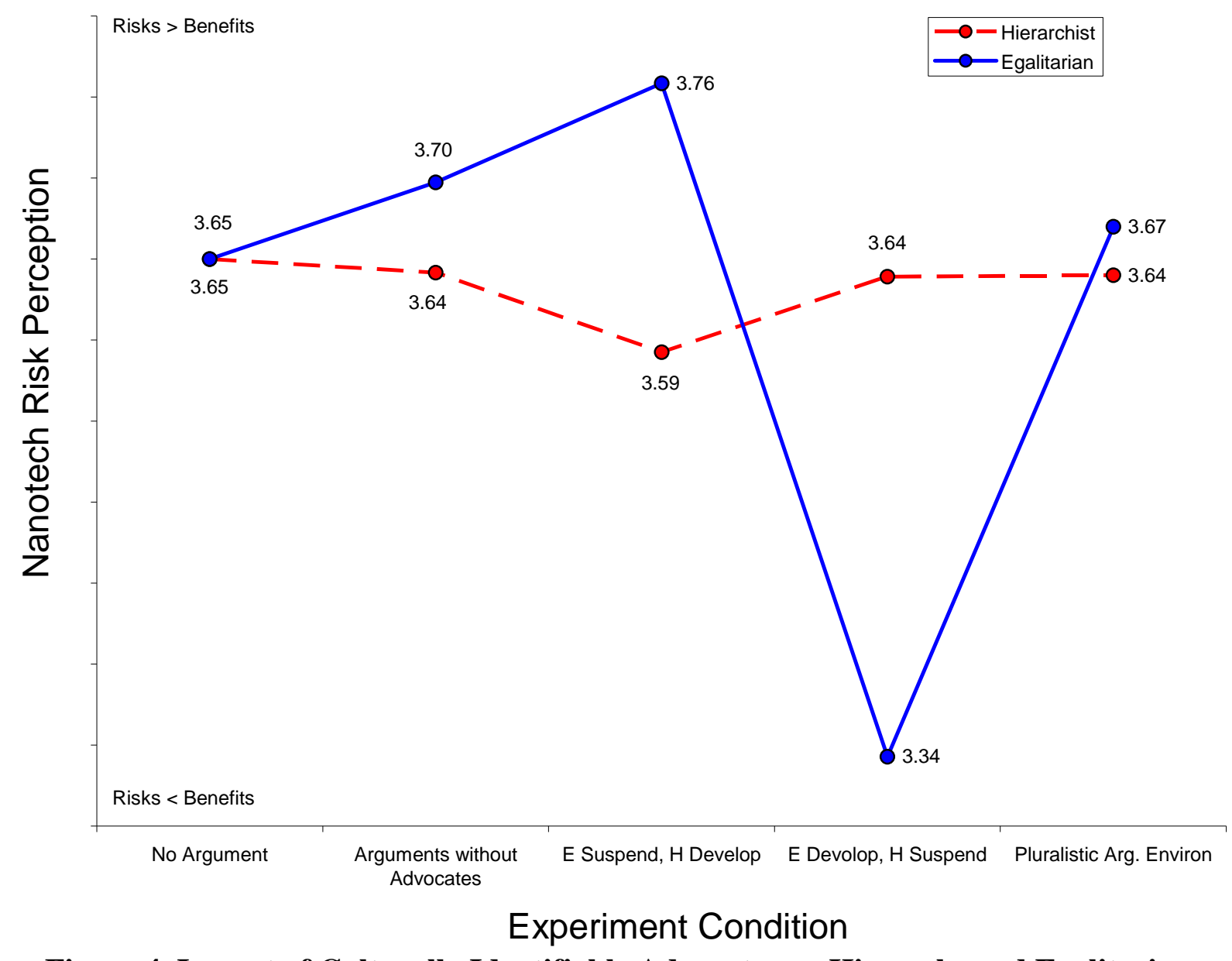

Figure 4. Impact of Culturally Identifiable Advocates on Hierarchs and Egalitarians

We found similar results along the individualism-communitarian dimension of cultural worldviews. When the advocate identifiable as holding a combination of Egalitarian and Communitarian views (Figure 3, lower right) defended suspension of development pending risk research, and the advocate identifiable as a combination of Hierarchical and Individualistic ones (Figure 3, upper left) defended continued development, polarization increased, mainly because that alignment increased the risk-skepticism of individualists. When the position of these advocates was reversed, polarization diminished. Other argument-advocate pairings produced lessdramatic results, possibly because a general correlation between individualism and hierarchy muted the credibility effect. Finally, in a pluralistic environment - one in which arguments both for and against continued development were as likely to be assigned an individualist advocate as to a communitarian one — there was, once more, relatively little polarization (Figure 5). ${ }^{8}$

\footnotetext{
${ }^{8}$ Differences in relative positions across conditions were statistically significant $(p<.05)$.
} 


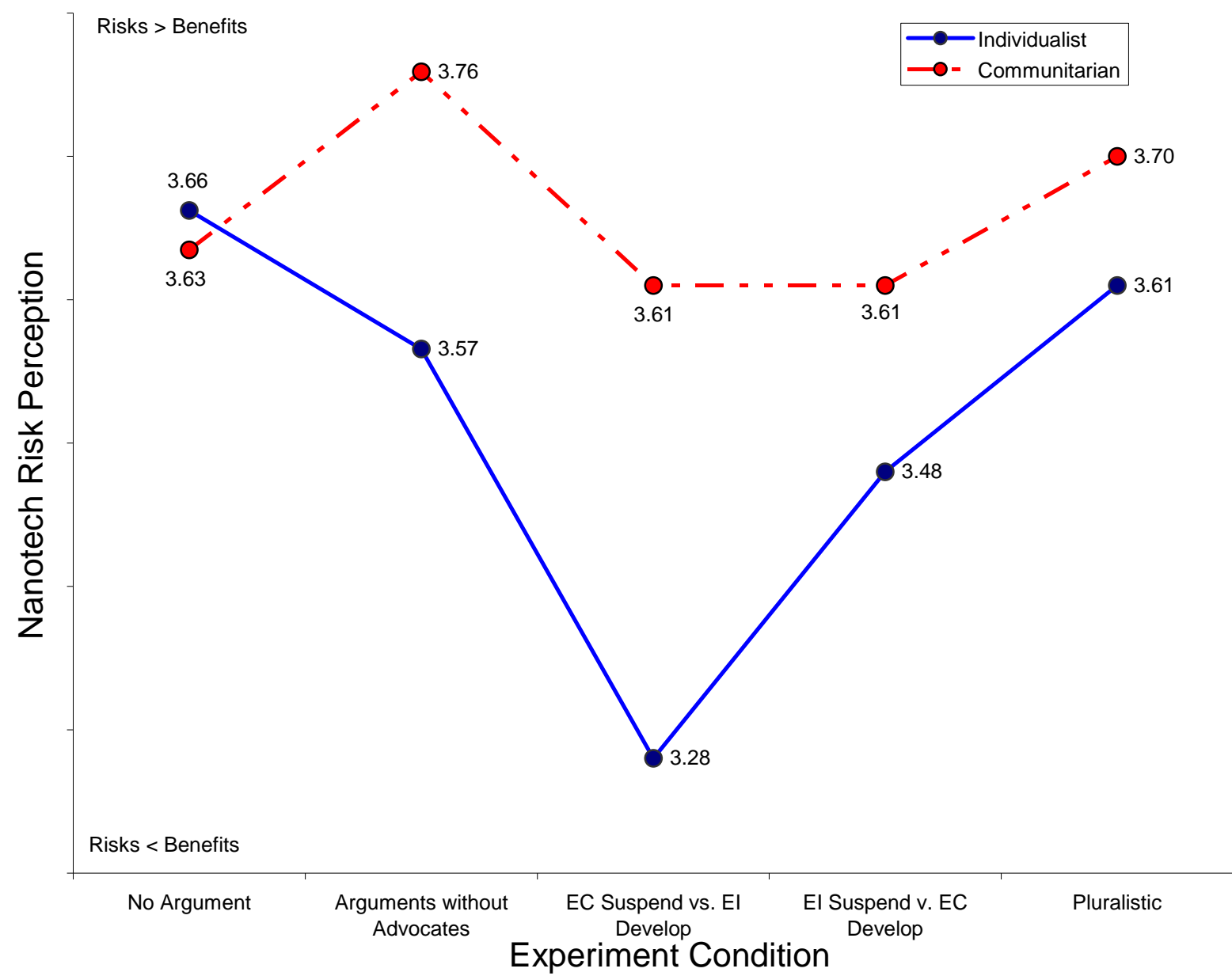

Figure 5. Impact of Culturally Identifiable Advocates on Individualists and Communitarians

\section{Conclusion: Lessons Learned and Issues Remaining to Be Investigated}

This most recent study in the CCP/PEN series yields a number of important insights. Some of these relate to the understanding of formation of risk perceptions generally. Others speak to how information about nanotechnology in particular should be conveyed in order to maximize the likelihood that public assessments reflect the best scientific understandings that are now available and that will become available in the future on nanotechnology's risks and benefits.

The first theoretically interesting lesson from this study relates to the profound significance of the cultural credibility heuristic in the formation of beliefs about novel risks. As shown in the first $\mathrm{CCP} / \mathrm{PEN}$ study and confirmed in this one, individuals process information about novel risks in diverse ways that reflect their disposition to reach conclusions congenial to their cultural values. But the current study shows that this type of biased assimilation appears to be much weaker than the tendency of persons to credit the assessments of experts and advocates 
whose cultural values they share. When those advocates take positions that reinforce individuals' cultural predispositions, the tendency of persons to form views in keeping with those predispositions is, not surprisingly, accentuated. But when those advocates take positions that contravene individuals' cultural predispositions, the impact of biased assimilation can be counteracted. Indeed, the normal association between positions on risk and particular cultural orientations can be completely inverted when advocates of opposing cultural identities simultaneously adopt positions contrary to the predispositions of individuals who share their respective outlooks. ${ }^{9}$

This finding enriches the general picture of the psychology of cultural cognition. It is well-known that individuals use heuristics to compensate for lack of firsthand knowledge with complicated issues of risk and for lack of the time and training necessary to acquire knowledge through engagement with scientific literature (Kahneman, Slovic, \& Tversky 1982). The theory of cultural cognition says that many of these heuristics possess an important connection to individuals' core values (Kahan, Slovic, Braman, \& Gastil 2006). The CCP/PEN studies of nanotechnology suggest that there is natural hierarchy among the heuristics that cultural cognition comprises. The first study suggested that individuals can make use of even a small bit of balanced information to orient themselves very rapidly on a novel issue of risk, likely as a result of their responsiveness to affective resonances in that information that allow individuals to assimilate their attitude toward a novel risk to more-familiar risk issues to which they have a culturally conditioned response (Kahan, Slovic, Braman, Gastil, \& Cohen 2007). But that initial heuristic judgment, the current study suggests, is not particularly robust. The positions taken by particular policy experts who share individuals' cultural values exert a much stronger heuristic influence on individuals as they try to make sense of a novel risk issue. Likely this is so because individuals assume that these policy advocates, whom they trust by virtue of a cultural affinity, have more knowledge about the risk issue in question than individuals themselves are able to acquire from the content of opposing sets of arguments. Alternatively, or perhaps simply in addition, the position of the expert might imply that the position the expert is espousing is in fact widely held by others who share that advocate's cultural outlooks, a cue that is likely subconsciously to induce listeners who hold that outlook to gravitate toward that view in order to affirm their connection with their cultural peers (Cohen 2003).

A number of important practical conclusions follow for those interested in assuring enlightened public deliberation on the risks and benefits of nanotechnology. One is reinforcement of the lesson that enlightened response to sound information cannot be taken for granted. Again, the existing positive correlation that exists between familiarity with nanotechnology and the perception that its benefits predominate over its risks in public opinion polls might be thought to imply that the simple dissemination of information about nanotechnology will generate a similarly positive view among that segment of the general population (the vast majority) currently unfamiliar with it. That position-which likely misunderstands the causal direction of the current relationship between a positive view of nanotechnology and familiarity with it—was shown to be false in the first CCP/PEN study.

\footnotetext{
${ }^{9}$ We obtained results similarly dramatic in independent experiments involving the cultural credibility heuristic and responses to arguments over the proposal for mandatory vaccination of school-age girls for human papillomavirus (Cultural Cognition Project 2007).
} 
The current study suggests that the expertise of persons disseminating information about nanotechnology also should not necessarily be expected to generate enlightened consensus about its risk and benefits. Just as individuals often lack the time and capacity to assess the soundness of information on their own, they also often lack the time and capacity to assess the training and knowledge of information providers. Moreover, on almost any risk issue of significance-from global warming to domestic terrorism, from school shootings to vaccination of school-age girls for human papillomavirus - members of the public will be confronted with dueling advocates whose expert credentials (scientific training, university affiliations, and the like) are roughly comparable. In that situation, they will almost certainly decide whom to trust in exactly the way they normally do, namely, by assessing who it is in the debate at hand who seems most like themselves. That judgment of likeness will almost certainly involve a tacit judgment of cultural affinity.

The impact of this cultural credibility heuristic can easily amplify the polarizing impact of simple information dissemination. The same forces that motivate individuals generally to adopt positions on risk issues that are congenial to their cultural outlooks can induce policy advocates to do so. As a result, a deliberative climate can emerge in which members of the public consistently see advocates they culturally identify with presenting arguments those members of the public are culturally predisposed to accept, and advocates they do not identify with presenting arguments they are culturally predisposed to reject. The state of public division that emerges when members of the public are impelled simultaneously by the combined forces of biased assimilation and cultural credibility makes the prospect for convergence on sound scientific information exceedingly remote.

Nevertheless, the results of the current study also vindicate the supposition that the polarizing tendencies of cultural cognition are not immutable. Precisely because the cultural credibility heuristic seems to exert greater force than the power of biased assimilation, it can, at least theoretically, be harnessed to counteract polarization.

The results of stage 2 of the study suggest that it is imperative that those who have a stake in enlightened public assessment of nanotechnology attend not just to what is said about its risks and benefits but also to who says it. It is critical that care be taken to avoid creating the impression in the mind of the public that one or another position on nanotechnology is strongly associated with one or another cultural outlook. Such an impression can easily arise by accident; indeed, it is likely in the nature of things for such an impression to emerge. To counteract it, proponents of enlightened decisionmaking should make a conscious effort to include as information providers experts and other risk communicators whom persons of diverse cultural outlooks will identify with and hence trust.

Even if it is a necessary part of any strategy to promote enlightened public deliberation on nanotechnology, securing a culturally pluralistic argument environment of this sort is unlikely to be sufficient. Studies suggest that information-framing techniques - in particular ones that affirm, rather than threaten, individuals' cultural values - also make a vital contribution to guaranteeing that individuals of diverse outlooks remain maximally receptive to sound information (Cultural Cognition Project 2007). In the absence of message framings that make sound information about nanotechnology's risk and benefits congenial to persons of diverse cultural outlooks, it will likely be impossible to foster or maintain culturally pluralistic advocacy of such information. Accordingly, experimental studies currently being conducted by CCP and PEN are aimed spe- 
cifically at adapting to nanotechnology information the sorts of identity-affirming framing techniques that have been used in other contexts.

Differences of opinion, to be worked out in the normal course of democratic decisionmaking, will almost certainly be a part of the future of nanotechnology in the United States. This will be so, at a minimum, because people naturally place different values on the myriad benefits that nanotechnology might confer and also on avoiding the types of risks that it might entail.

But no matter how they come out on these questions, citizens of diverse values have a common interest in ensuring that their deliberations are informed by the very best understanding of nanotechnology's risks and benefits that science is able to attain. They have a common interest, then, in creating a deliberative climate that is free of influences that impede their capacity to recognize what that information is.

The CCP/PEN studies show that the dynamics of cultural cognition can be one of those influences. But the studies also show that it is possible to devise procedures of information dissemination that counteract this source of distortion. Continued development of a comprehensive strategy for furnishing information accessible to persons of diverse cultural outlooks should be among the highest priorities of those who want to promote enlightened public debate on this important and novel science. 


\section{Bibliography}

Cohen, G. L. (2003). Party over Policy: The Dominating Impact of Group Influence on Political Beliefs. Journal of Personality \& Social Psychology, 85(5), 808-822.

Cultural Cognition Project (2007). The Second National Risk and Culture Study: Making Sense of - and Making Progress in - the American Culture War of Fact, http://papers.ssrn.com/sol3/papers.cfm?abstract_id=1017189.

DiMaggio, P. (1997). Culture and Cognition. Annual Review of Sociology, 23, 263-287.

Douglas, M., \& Wildavsky, A. B. (1982). Risk and Culture: An Essay on the Selection of Technical and Environmental Dangers. Berkeley, CA: University of California Press.

Kahan, D. M., \& Braman, D. (2006). Cultural Cognition of Public Policy. Yale Journal of Law and Public Policy, 24, 147-170, http://papers.ssrn.com/sol3/papers.cfm?abstract id=746508.

Kahan, D.M., Braman, D., Slovic, P., Gastil, J. \& Cohen, G. (2008) The Future of Nanotechnology Risk Perceptions: An Experimental Investigation of Two Hypotheses, Cultural Cognition Working Paper No. 46, http://papers.ssrn.com/sol3/papers.cfm?abstract_id=1089230.

Kahan, D. M., Braman, D., Gastil, J., Slovic, P., \& Mertz, C. K. (2007). Culture and IdentityProtective Cognition: Explaining the White-Male Effect in Risk Perception. Journal of Empirical Legal Studies, 4(3), 465-505, http://papers.ssrn.com/sol3/papers.cfm?abstract_id=995634.

Kahan, D. M., Slovic, P., Braman, D., \& Gastil, J. (2006). Fear of Democracy: A Cultural Critique of Sunstein on Risk. Harvard Law Review, 119, 1071-1109, http://www.harvardlawreview.org/issues/119/feb06/kahan.pdf.

Kahan, D. M., Slovic, P., Braman, D., Gastil, J., \& Cohen, G. L. (2007). Affect, Values, and Nanotechnology Risk Perceptions: An Experimental Investigation. Cultural Cognition Working Paper No. 22, http://papers.ssrn.com/sol3/papers.cfm?abstract id=968652.

Kahneman, D., Slovic, P., \& Tversky, A. (1982). Judgment Under Uncertainty: Heuristics and Biases. New York: Cambridge University Press.

Lord, C. G., Ross, L., \& Leper, M. R. (1979). Biased Assimilation and Attitude Polarization: The Effects of Prior Theories on Subsequently Considered Evidence. Journal of Personality \& Social Psychology, 11, 2098-2109.

Peter D. Hart Research Associates. (2007). Awareness of and Attitudes Toward Nanotechnology and Federal Regulatory Agencies, http://www.nanotechproject.org/file download/217. 


\section{Appendix A. Select Experiment Survey Instrument Items}

\section{Cultural Orientation Scales}

Six-point response scale for all items: Strongly Disagree, Moderately Disagree, Slightly Disagree, Slightly Agree, Moderately Agree, and Strongly Agree.

Individualism-Solidarism Scale

1. IINTRSTS. The government interferes far too much in our everyday lives.

2. SHARM. Sometimes government needs to make laws that keep people from hurting themselves.

3. IPROTECT. It's not the government's business to try to protect people from themselves.

4. IPRIVACY. The government should stop telling people how to live their lives.

5. SPROTECT. The government should do more to advance society's goals, even if that means limiting the freedom and choices of individuals.

6. SLIMCHOI. Government should put limits on the choices individuals can make so they don't get in the way of what's good for society.

7. SNEEDS. It's society's responsibility to make sure everyone's basic needs are met.

8. INEEDY. It's a mistake to ask society to help every person in need.

9. SRELY. People should be able to rely on the government for help when they need it.

10. IRESPON. Society works best when it lets individuals take responsibility for their own lives without telling them what to do.

11. ITRIES. Our government tries to do too many things for too many people. We should just let people take care of themselves.

12. IFIX. If the government spent less time trying to fix everyone's problems, we'd all be a lot better off.

13. IENJOY. People who are successful in business have a right to enjoy their wealth as they see fit.

14. IMKT. Free markets - not government programs - are the best way to supply people with the things they need.

15. IPROFIT. Private profit is the main motive for hard work. and money.

16. IGOVWAST. Government regulations are almost always a waste of everyone's time 


\section{Hierarchy-Egalitarianism Scale}

1. HEQUAL. We have gone too far in pushing equal rights in this country.

2. HREVDIS1. Nowadays it seems like there is just as much discrimination against whites as there is against blacks.

3. EWEALTH. Our society would be better off if the distribution of wealth was more equal.

4. ERADEQ. We need to dramatically reduce inequalities between the rich and the poor, whites and people of color, and men and women.

5. EDISCRIM. Discrimination against minorities is still a very serious problem in our society.

6. HREVDIS2. It seems like blacks, women, homosexuals and other groups don't want equal rights, they want special rights just for them.

7. HCHEATS. It seems like the criminals and welfare cheats get all the breaks, while the average citizen picks up the tab.

8. EDIVERS. It's old-fashioned and wrong to think that one culture's set of values is better than any other culture's way of seeing the world.

9. HWMNRTS. The women's rights movement has gone too far.

10. ESEXIST. We live in a sexist society that that is fundamentally set up to discriminate against women.

11. HTRADFAM. A lot of problems in our society today come from the decline in the traditional family, where the man works and the woman stays home.

12. HFEMININ. Society as a whole has become too soft and feminine.

13. EROUGH. Parents should encourage young boys to be more sensitive and less rough and tough.

\section{Environmental Risk Items}

Six-point response scale for all items: Strongly Disagree, Moderately Disagree, Slightly Disagree, Slightly Agree, Moderately Agree, and Strongly Agree.

1. GWPOLICY. It is important to take steps to reduce global warming.

2. GWRISK. Global warming poses a serious environmental risk.

3. NUCDANGER. It is dangerous to live near a nuclear power plant.

\section{Nanotechnology Familiarity Item}

PRIORKNOW. Before today, how much would you say you knew about nanotechnology? [Nothing, A Little, A Moderate Amount, A Lot] 


\section{Balanced Arguments}

Juxtaposed and rotated; assign randomly to advocates in Stage 2 credibility experiment.

Develop Now, Regulate later. Nanotechnology is likely to create immense benefits for society. Some examples are food containers that kill bacteria, stain-resistant clothing, highperformance sporting goods, faster and smaller computers, and more effective skincare products and sunscreens. Nanotechnology also has the potential to create better ways to treat disease, clean up the environment, enhance national security, and provide cheaper energy. It's fine for government to study and monitor the nanotechnology industry as it develops. But if restrictive government regulations discourage companies from making the necessary start-up investments in this new technology, society will suffer for sure.

\section{Nanotechnology Risk-Benefit Items}

Six-point response scale for all items: Strongly Disagree, Moderately Disagree, Slightly Disagree, Slightly Agree, Moderately Agree, and Strongly Agree.

1. NANOBENEFIT. The benefits of nanotechnology are likely to be very large.

2. NANORISK. The risks of nanotechnology are likely to be very large.

3. NANOBALANCE. On the whole, the benefits of nanotechnology will outweigh the risks.

4. SAFETYFIRST. Government should prohibit commercial development of nanotechnology until studies have been done on how to control any risks nanotechnology might involve.

5. GOFORIT. Restricting commercial development of nanotechnology until more studies are done is a bad idea because it will discourage essential investments in the nanotechnology industry.

6. PRECAUTION. In the face of uncertainty about risk, the best course of action is to conduct safety studies before allowing nanotechnology to be developed.

7. OPPCOST. Preventing development of nanotechnology while safety studies are being done will deprive society of too many potential benefits from nanotechnology. 


\section{Appendix B. Study Sample.}

\section{Knowledge Networks}

Study subjects consisted of a nationally representative general population sample of approximately 1,600 Americans who were recruited by Knowledge Networks and who participated in study experiments via Knowledge Network's on-line testing facilities. Knowledge Networks (http://www.knowledgenetworks.com/) is a public opinion research firm with offices located throughout the United States. It maintains an active respondent pool of some 40,000 persons who are recruited to participate in on-line surveys and experiments administered on behalf of academic and governmental researchers and private businesses. Knowledge Network respondents agree to participate in three to four surveys per month in exchange for Internet access and other forms of compensation. It uses recruitment and sampling methods that assure a diverse sample that is demographically representative of the U.S. population. Numerous studies have concluded that on-line testing of Knowledge Network samples generates results equivalent in their reliability to conventional random-digit-dial surveys (http://www.knowledgenetworks.com/ganp/2005aapor.html, and studies using Knowledge Networks facilities are routinely published in peer-reviewed academic journals (http://www.knowledgenetworks.com/ganp/docs/List\%20of\%20Journals\%208-28-2006.pdf).

2. Demographic composition of sample for this study

a. Gender: $51 \%$ female, $49 \%$ male.

c. Race: $73 \%$ white, 9\% African-American.

d. Average age: 47 years.

e. Median household income: $\$ 35,000$ to $\$ 40,000$.

f. Median education level: Some college. 